\title{
KAJIAN PERTUMBUHAN TEGAKAN HYBRID Eucalyptus urograndis DI SUMATERA UTARA
}

\section{Growth of Eucalyptus urograndis Hybrid in North Sumatera}

\author{
Nina Mindawati ${ }^{1)}$, Andry Indrawan ${ }^{2)}$, Irdika Mansur ${ }^{2)}$ dan/and Omo Rusdiana ${ }^{2)}$ \\ ${ }^{1)}$ Pusat Litbang Hutan Tanaman, Kampus Balitbang Kehutanan \\ Jl. Gunung Batu No. 5 Bogor 16610, Telp. (0251) 8631238, Fax. (0251) 7520005 \\ ${ }^{2)}$ Fakultas Kehutanan, Institut Pertanian Bogor \\ Kampus Darmaga, Jl. Raya Darmaga, Bogor
}

Naskah masuk : 1 April 2009; Naskah diterima : 11 Januari 2010

\begin{abstract}
Growth of stands is the increment was diameter, volume or basal area of trees within a certain period. The growth model used to predict the productivity and that is very useful in forest management planning. Study modeled growth of Eucalyptus urograndis species of 1 and 2 rotation have been done in 2009 at PT Toba Pulp Lestari, sector Aek Nauli, North Sumatra with the aims of comparing the growth of these species between 1 and 2 rotation, and to determine the optimal volume cycle. Study was conducted by using data from the PSP (Permanent sample plots) are measured periodically and the data of instantaneous measurements of TSP (Temporary Sample plots) of various age stands. The results of the study found that the prediction of growth of E. urograndis could follow the equation for high $(H)$, diameter (D) and volume (V) as follows: $\ln H=3.40434-1.73745$ (1/age); $\ln D=2.99598-1.56925$ (1 / age); $\ln V$ $=6.300505-5.63547$ (1/age) with the optimal volume cycle achieved in 5.5 years for rotation 1 and equation: $\ln H=3.342944-1.5336$ (1/age); $\ln D=2.987992-1.44311$ (1/age) and $\ln V=6.205122$ 5.06804 (1/age) with the optimal volume cycle achieved in year 5 for rotation 2. Growth model and the same techniques can be used to type E. urograndis on environmental conditions are relatively similar.
\end{abstract}

\section{Keywords: Rotation, growth, Eucalyptus urograndis, permanent plots}

\begin{abstract}
ABSTRAK
Pertumbuhan tegakan adalah pertambahan (riap) dari suatu besaran seperti tinggi, diameter, volume atau luas bidang dasar pohon dalam periode tertentu. Model pertumbuhan digunakan untuk menduga besaran produktivitas dan sangat berguna dalam perencanaan pengelolaan hutan tanaman suatu jenis pohon. Kajian model pertumbuhan jenis Eucalyptus urograndis telah di lakukan tahun 2009 di PT Toba Pulp Lestari, sektor Aek Nauli, Sumatera Utara pada rotasi 1 dan rotasi 2 dengan tujuan untuk membandingkan pertumbuhan jenis tersebut antara rotasi 1 dan rotasi 2, dan menentukan daur volume optimalnya. Kajian dilakukan dengan menggunakan data dari PSP (Permanent Sample Plots) yang diukur secara periodik dan data hasil pengukuran sesaat pada TSP (Temporary Sample Plots) dari berbagai umur tegakan. Hasil kajian mendapatkan bahwa pendugaan pertumbuhan jenis $E$. urograndis dapat mengikuti persamaan tinggi $(\mathrm{H})$, diameter (D) dan volume (V) sebagai berikut : $\ln \mathrm{H}=3,40434$ - 1,73745 (1/umur); $\ln \mathrm{D}=$ 2,99598 - 1,56925 (1/umur); ln V =6,300505 - 5,63547 (1/umur) dengan daur volume optimal dicapai pada tahun 5,5 tahun untuk rotasi 1 dan persamaan : $\ln \mathrm{H}=3,342944$ - 1,5336 (1/umur); $\ln \mathrm{D}=2,987992$ 1,44311 (1/umur) dan $\ln \mathrm{V}=6,205122$ - 5,06804 (1/umur) dengan daur volume optimal dicapai pada tahun ke 5 untuk rotasi 2. Model pertumbuhan dan teknik yang sama dapat digunakan untuk jenis $E$. urograndis pada kondisi lingkungan yang relatif sama.
\end{abstract}

Kata kunci : Daur, Eucalyptus urograndis, pertumbuhan, petak ukur permanen 


\section{PENDAHULUAN}

\section{A. Latar Belakang}

Salah satu bentuk HTI yang saat ini memegang peranan penting dalam menunjang pengembangan industri kayu serat domestik adalah HTI-kayu serat atau HTI-Pulp. Pentingnya pembangunan HTI-Pulp antara lain dapat dilihat dari kenyataan besarnya ketergantungan jenis industri ini kepada kayu serat. Serat dapat dihasilkan dari bahan yang mengandung selulosa tinggi seperti kayu, kenaf, bambu dan lainnya. Namun pada saat ini lebih dari $90 \%$ bahan baku pulp dan kertas berasal dari kayu, karena kayu mempunyai sifat unggul yaitu : rendemen yang dihasilkan tinggi, kandungan lignin relatif rendah dan kekuatan pulp dan kertas yang dihasilkan tinggi (Pasaribu dan Tampubolon, 2007).

Eucalyptus spp. seperti jenis Eucalyptus urophylla, E. grandis dan E. pelita merupakan jenis tumbuh cepat yang dikembangkan sebagai bahan baku industri pulp secara luas di PT Toba Pulp Lestari dengan daur tebang 7-8 tahun. Selain itu, jenis Eucalyptus hibrid seperti $E$. urograndis (E. urophylla $x$ E. grandis) terseleksi telah berhasil dikembangkan secara luas dengan karakter pertumbuhan yang lebih baik jika dibanding tanaman tetuanya. Pengembangan hibrid Eucalyptus di Indonesia masih tertinggal dibanding dengan negara lain seperti China, Congo, Brazil dan Afrika Selatan yang telah mengusahakan hibrid Eucalyptus secara komersil dengan perbanyakan vegetatif (Nikles, 1996).

Hasil-hasil penelitian tentang pertumbuhan atau produktivitas tegakan $E$. urograndis telah banyak dilakukan di Australia, Brazil dan China, sedangkan di Indonesia jenis $E$. urograndis belum lama dikembangkan secara luas sehingga hasil penelitian masih sangat sedikit dan bersifat parsial. Budidaya $E$. urograndis di Brazil telah menghasilkan pertumbuhan pohon yang spektakuler, seragam dan kemampuan pangkas yang tinggi. Menurut Gonçalves et al. (1997) pertumbuhan E. urograndis di Brazil pada tanah ultisol sangat beragam dengan kisaran riap rata-rata tahunan (mean annual increment: MAI) pada umur 5 tahun sebesar $1248 \mathrm{~m}^{3} /$ ha/tahun. Sedangkan di Congo produktivitas hibrid E. urograndis sangat tinggi dan memiliki riap tahunan rata-rata sebesar $70 \mathrm{~m}^{3} /$ ha/tahun (Campinhos, 1993).

Penelitian tentang pertumbuhan jenis $E$. urograndis penting untuk dilakukan karena akan sangat berguna dalam perencanaan pengelolaan hutan tanaman jenis E. urograndis dan merupakan salah satu kunci yang mendukung keberhasilan pembangunan hutan tanaman industri di Indonesia secara berkelanjutan di masa depan.

\section{B. Tujuan}

Tujuan penelitian adalah untuk mengetahui perbandingan partumbuhan jenis $E$. urograndis rotasi 1 dan rotasi 2 serta menentukan daur volume maksimum.

\section{BAHAN DAN METODE}

\section{A. Lokasi}

Penelitian telah dilakukan di Aek Nauli, Sumatera Utara yang secara geografis terletak antara $2^{\circ} 40^{\prime} 00^{\prime \prime}$ - $2^{\circ} 50^{\prime} 00^{\prime \prime}$ Lintang Utara dan $98^{\circ} 50^{\prime} 00^{\prime \prime}-98^{\circ} 10^{\prime} 00^{\prime \prime}$ Bujur Timur dengan ketinggian $1200 \mathrm{~m}$ di atas permukaan laut (Toba Pulp Lestari, 2009). Peta lokasi penelitian dapat dilihat pada Gambar 1. 


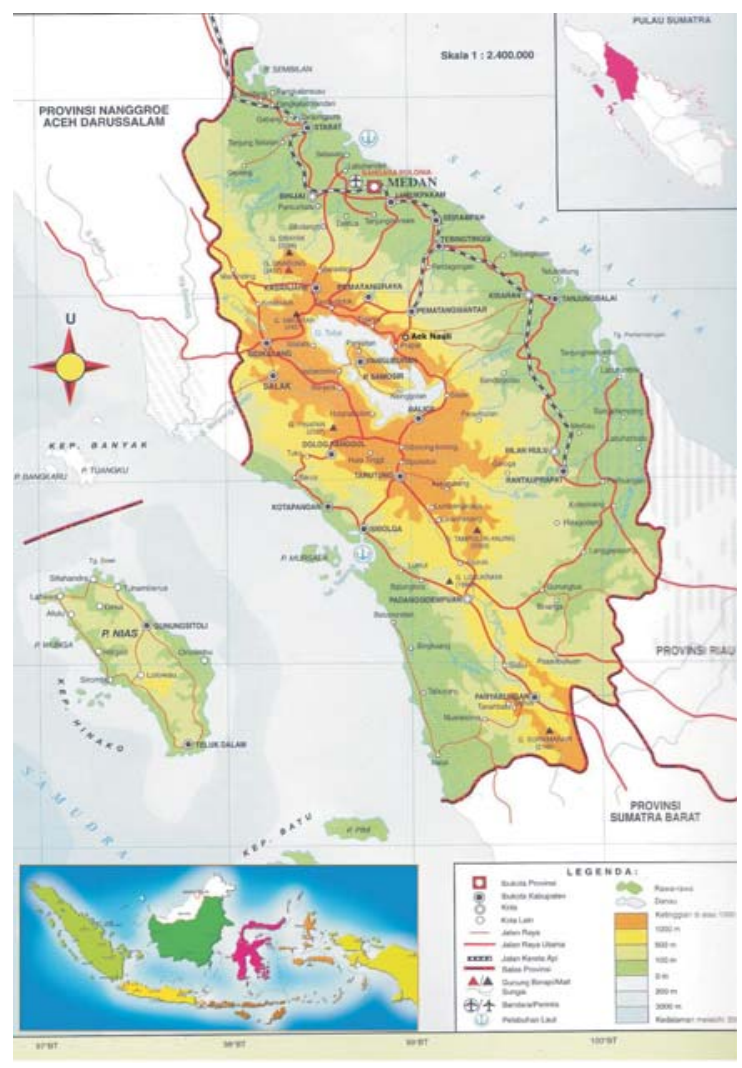

Gambar (Figure) 1. Peta lokasi penelitian di Aek Nauli, Simalungun, Sumatera Utara (Map of research location at Nauli, Simalungun, North Sumatra)

\section{B. Bahan dan Alat}

Bahan penelitian adalah data primer hasil pengukuran petak ukur permanen (PUP) tegakan E. urograndis umur 1, 2, 3, 4 dan 5 tahun pada rotasi 1 dan 2. Sedangkan alat penelitian adalah alat ukur tinggi dan diameter pohon berupa vertex, tali rafia, cat, golok dan lain-lain.

\section{Metode}

1. Pengumpulan data

a. Data primer

Pengumpulan data primer dilakukan dengan membuat plot penelitian pada areal plot TSP (Temporary Sample Plot) dengan luas setiap plot 0,004 hektar yang berukuran $20 \times 20$ meter. Plot TSP dibuat pada tegakan E. urograndis rotasi 1 umur 1, 2, 3, 4 dan 5 tahun berturut-turut di petak D022, A072, A045, A024, dan A079, dan rotasi 2 umur 1, 2, 3, 4 dan 5 tahun pada petak: C004, C031, B010, B067 dan B028. Ulangan dilakukan sebanyak 3 kali sehingga jumlah petak seluruhnya sebanyak 30 petak percobaan.

Data parameter pertumbuhan pohon yang diukur pada setiap plot adalah, tinggi pohon (tree height: $h_{t}$ ) dan diameter batang pohon setinggi dada (diameter at breast height: $d_{t}$ ) dari seluruh pohon yang ada dalam TSP.

\section{b. Data sekunder}

Pengumpulan data dilakukan dengan mengambil data sekunder hasil pengukuran pada petak ukur permanen (Permanen Sample Plot' PSP) jenis E. urograndis di sektor Aek Nauli, luas masing-masing PSP berkisar 0,02 - 0,08 hektar tiap kelas umur. Data yang dikum-pulkan adalah seluruh data pertumbuhan jenis E. urograndis yang ada di PSP di Sektor Aek Nauli dan diasumsikan mewakili kondisi tegakan secara keseluruhan untuk tiap umur tegakan pada rotasi 1 dan 2. Jumlah seluruh PSP yang dikum-pulkan datanya untuk penelitian ini adalah sebanyak 43 PSP terdiri dari 14 petak pada rotasi 1 dan 29 petak pada rotasi 2 pada berbagai umur tegakan yang berkisar antara umur 1,8 bulan sampai umur 6 tahun.

Data parameter pertumbuhan tegakan yang dikumpulkan dari tiap PSP adalah umur tegakan, tinggi pohon (tree height: $h_{t}$ ), diameter batang pohon setinggi dada (diameter at breast height: $d_{t}$ ) dan volume yang termanfaatkan dari seluruh pohon dalam masing-masing PSP. 


\section{Pengolahan data}

a. Tinggi tegakan

Avery dan Burkhart (2002) serta Husch et al. (2003) menyatakan bahwa tinggi tegakan adalah nilai rata-rata dari tinggi semua pohon dalam tegakan yang bersangkutan. Oleh karena itu tinggi tegakan dalam tiap PSP dihitung dengan Persamaan 1.

$H_{s_{i}} \sum \frac{\sum_{j \sum 1}^{N_{i}} h_{t_{i j}}}{N_{i}}$

dimana:

$H_{s i} \quad$ : Tinggi tegakanPSP ke- $i$.

$h_{t i j} \quad: \quad$ tinggi pohon ke-j dalam PSP ke- $i$.

$N_{i} \quad$ : jumlah pohon dalam PSP ke- $i$.

\section{b. Diameter tegakan}

Diameter tegakan adalah nilai rata-rata dari diameter semua pohon dalam tegakan yang bersangkutan (Avery dan Burkhart, 2002; Husch et al., 2003), sehingga diameter tegakan dalam tiap PSP dihitung dengan Persamaan 2.

$D_{s_{i}} \sum \frac{\sum_{j \Sigma l}^{N_{i}} d_{t_{i j}}}{N_{i}}$

dimana :

$D_{s i} \quad$ : diameter tegakan PSP ke-i

$D_{t i j} \quad:$ diameter pohon ke-j dalam PSP ke- $i$

$N_{i} \quad$ : jumlah pohon dalam PSP ke- $i$

\section{c. Volume tegakan}

Volume termanfaatkan (merchantable volume) tiap pohon dihitung berdasarkan diameter dan tinggi pohon yang bersangkutan dengan menggunakan persamaan yang telah dihasilkan oleh perusahaan (Toba Pulp Lestari, 2009), yaitu dalam bentuk Persamaan 3 .

$$
v_{m_{i j}}=e^{-11,7738+2,2617 \ln d_{t_{i j}}+1,1975 \ln h_{t_{i j}}}
$$

dimana :

$v_{m i j} \quad:$ merchantable volume pohon ke-j dalam PSPke-i

$d_{t i j} \quad:$ diameter pohon ke-j dalam PSP ke- $i$

$h_{i j} \quad$ : tinggi pohon ke-j dalam PSP ke- $i$
Merchantable volume tegakan $\left(V_{m}\right)$ tiap PSP adalah jumlah volume termanfaatkan semua pohon dalam PSP yang bersangkutan; dan prediksi volume tegakan tiap hektar adalah hasil transformasinya berdasar luas PSP.

$V_{m_{i}} \sum \frac{10.000}{200} \sum_{j \Sigma 1}^{N_{i}} v_{m_{i j}}$

dimana :

$v_{m i} \quad$ : prediksi volume tegakan tiap hektar berdasar merchantable volume tegakan PSP ke- $i$

$N_{i} \quad$ : jumlah pohon dalam PSP ke- $i$

$V_{m i j} \quad$ : merchantable volume pohon ke-j dalam PSP ke- $i$

\section{d. Model hasil tegakan}

Model hasil tegakan dibuat untuk memprediksi besaran-besaran tegakan E. urograndis berdasarkan umur tegakannya dalam bentuk model matematis yang menggambarkan hubungan fungsional antara parameter biologik (tinggi, diameter, dan volume) dengan umur tegakan pada rotasi 1 dan 2. Model hasil disusun dalam bentuk persamaan eksponensial (Alder, 1980) dengan analisis regresi bersarang (nested regression):

$$
\begin{aligned}
& \operatorname{Ln} H_{s}=a+b \frac{1}{A} \\
& \text { Ln } D_{s}=a+b \frac{1}{A} \\
& \text { Ln } V_{m}=a+b \frac{1}{A}
\end{aligned}
$$

dimana :

$H_{s} \quad$ : tinggi tegakan (m)

$D_{s} \quad:$ diameter tegakan $(\mathrm{cm})$

$V_{m}:$ merchantable volume tegakan $\left(\mathrm{m}^{3} / \mathrm{ha}\right)$

$A \quad$ : umur tegakan (tahun)

\section{e. Uji kesahihan model}

Tingkat kesahihan (validity) masingmasing model didasarkan pada besarnya koefisien determinasi terkoreksi (adjusted coefficient of determination). 


$$
R_{a d j}^{2}=1-\frac{\frac{S S E}{n-1-p}}{\frac{S S T}{n-1}}
$$

dimana :

$$
\begin{array}{ll}
R_{a d j}^{2} & : \text { koefisien determinasi terkoreksi } \\
S S E & : \text { jumlah kuadrat sisaan } \\
S S T & : \text { jumlah kuadrat total } \\
p & : \text { jumlah peubah tidak bergantung dalam } \\
& \text { model } \\
n & : \text { jumlah sampel }
\end{array}
$$

Selain penghitungan koefisien determinasi terkoreksi, dalam penelitian ini kesahihan model juga diukur melalui uji silang (cross validation) dengan membandingkan nilai dugaan (menggunakan model) versus nilai aktual data independen. Data independen berupa hasil pengukuran petak ukur temporer (Temporary Sample Plots: TSP) di berbagai umur tegakan. Uji silang dilakukan dengan menghitung nilai efisiensi model tereduksi (the adjusted model efficency: $M E F_{a d j}$ ) dan nilai khi-kuadrat (chisquare: $\left.\chi^{2}\right) . M E F_{a d j}$ dihitung dengan Persamaan 9 (Soares et al., 1995; Vanclay dan Skovsgaard, 1997; Huang et al., 2003), sedangkan penghitungan $\chi^{2}$ mengikuti Persamaan 10 seperti disarankan Steel dan Torrie (1980), Sokal dan Rohlf(1995), serta Kutner et al. (2005).

$$
\begin{gathered}
M E F_{a d j} \sum 1 \sum \frac{\left(n \sum 1\right) \sum_{i \unrhd}^{n}\left(y_{i} \sum \hat{y}_{i}\right)^{2}}{\left(n \sum p\right) \sum_{i \unrhd}^{n}\left(y_{i} \sum \bar{y}_{i}\right)^{2}} \\
\sum^{2} \sum \sum_{l \Sigma 1}^{n} \frac{\sum_{i} \sum \hat{y}_{i} \sum}{\hat{y}_{i}}
\end{gathered}
$$

dimana :

$$
\begin{array}{ll}
M E F_{a d j}: & \text { efisiensi model tereduksi } \\
X^{2} & : \text { khi-kuadrat } \\
y_{i} & : \text { nilai aktual parameter tegakan pada data } \\
& \text { independen } \\
y_{i} & : \text { nilai dugaan parameter tegakan ber- } \\
& \text { dasar model hasil } \\
y_{i} & : \text { rataan nilai aktual parameter tegakan } \\
& \text { pada data independen } \\
n & : \text { jumlah TSP data independen } \\
p & : \begin{array}{l}
\text { : jumlah peubah tidak bergantung pada } \\
\text { model hasil }
\end{array}
\end{array}
$$

\section{f. Daur volume optimal}

Daur volume optimal dicapai pada saat riap rata-rata tahunan (Mean Annual Increment: MAI) maksimum. Oleh karena itu penetapan daur volume maksimum dilakukan dengan membuat grafik hubungan antara umur dengan riap ratarata tahunan dan grafik hubungan antara umur dengan riap rata-rata periodik (Current Annual Increment: $C A I$ ) dimana riap rata-rata tahunan maksimum berada pada titik perpotongan grafik $M A I$ dengan grafik $C A I$.

\section{HASIL DAN PEMBAHASAN}

\section{A. Model Pertumbuhan Tegakan E. urograndis}

Pertumbuhan diartikan sebagai pertambahan dimensi pohon atau tegakan hutan selama periode waktu tertentu (Vanclay, 1994). Pertumbuhan tegakan merupakan proses pertambahan (riap) dari suatu besaran tegakan dalam periode tertentu. Besaran pertumbuhan yang juga disebut riap tegakan dapat dilihat dari parameter tinggi, diameter atau volume. Oleh karena itu, dinamika pertumbuhan pohon/tegakan dapat diduga dengan menggunakan suatu model matematis hubungan antara parameter-parameter pertumbuhan: jumlah pohon, luas bidang dasar, diameter, tinggi maupun umurnya. Model matematis yang disusun akan dapat digunakan untuk memproyeksikan hasil tegakan yang akan dipanen secara lestari diakhir rotasi yang ditetapkan.

Dari hasil pengukuran dimensi tegakan yaitu tinggi dan diameter di lapangan pada setiap umur tegakan, juga berdasarkan perhitungan volume tiap umur tegakan, terlihat hubungan yang relatif linier antara tinggi, diameter dan volume dengan umur tegakan. Artinya semakin besar umur tegakan maka dimensi pertumbuhan semakin tinggi sampai umur 5 tahun, dalam penelitian ini baik pada rotasi 1 maupun rotasi 2 . Dari grafik pertumbuhan tinggi terlihat bahwa pada rotasi 1 dan 2 hampir sama kecuali di akhir daur yaitu pada tahun ke lima terjadi perbedaan tinggi dimana tinggi pada rotasi 1 lebih tinggi besarannya dibanding rotasi 2 (Gambar 2). Pertumbuhan diameter pada rotasi 2 tidak terjadi penurunan dan relatif sama dengan rotasi 1 . Hal ini ditunjukan oleh kurva yang cenderung berhimpit (Gambar 3) dan begitu pula nilai volume pada rotasi 1 hampir sama dengan rotasi 2 (Gambar 4). 


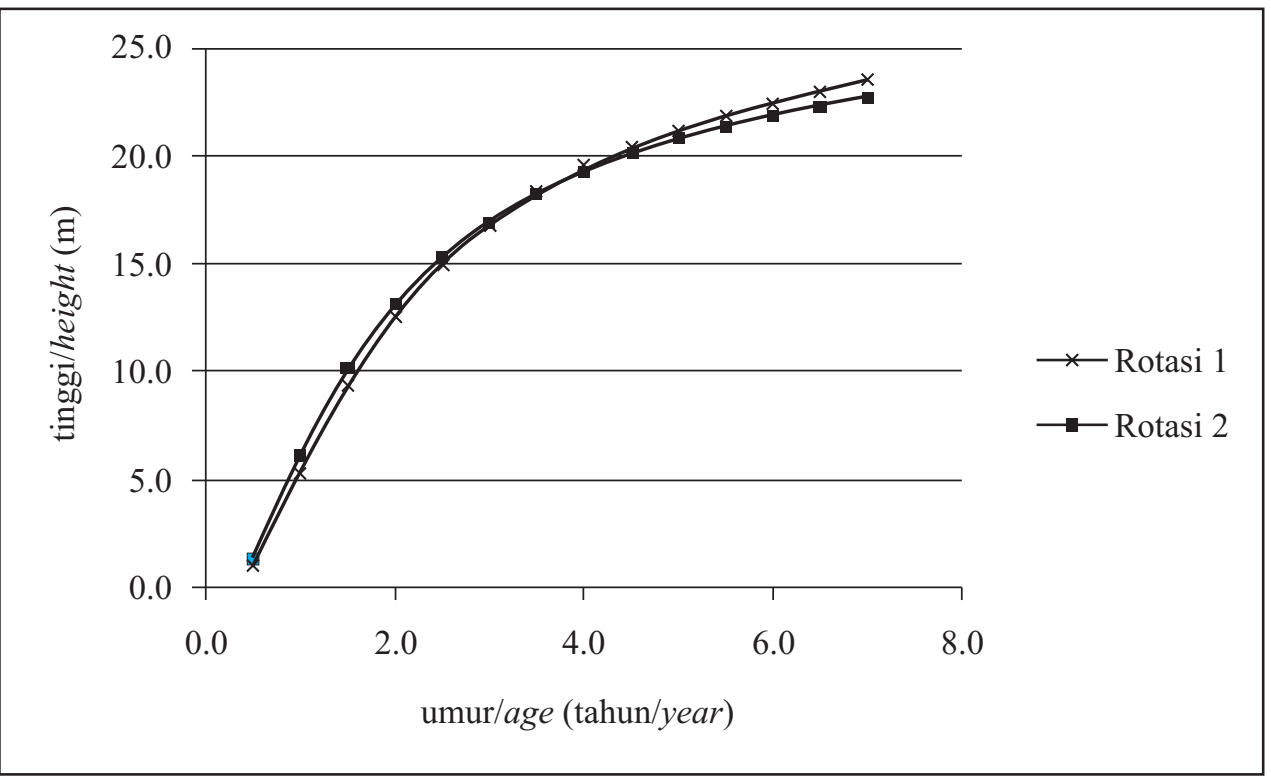

Gambar(Figure) 2. Kurva hubungan antara tinggi dan umur tegakan E. urograndis (Curve of the correlation between height and ages of E. urograndis)

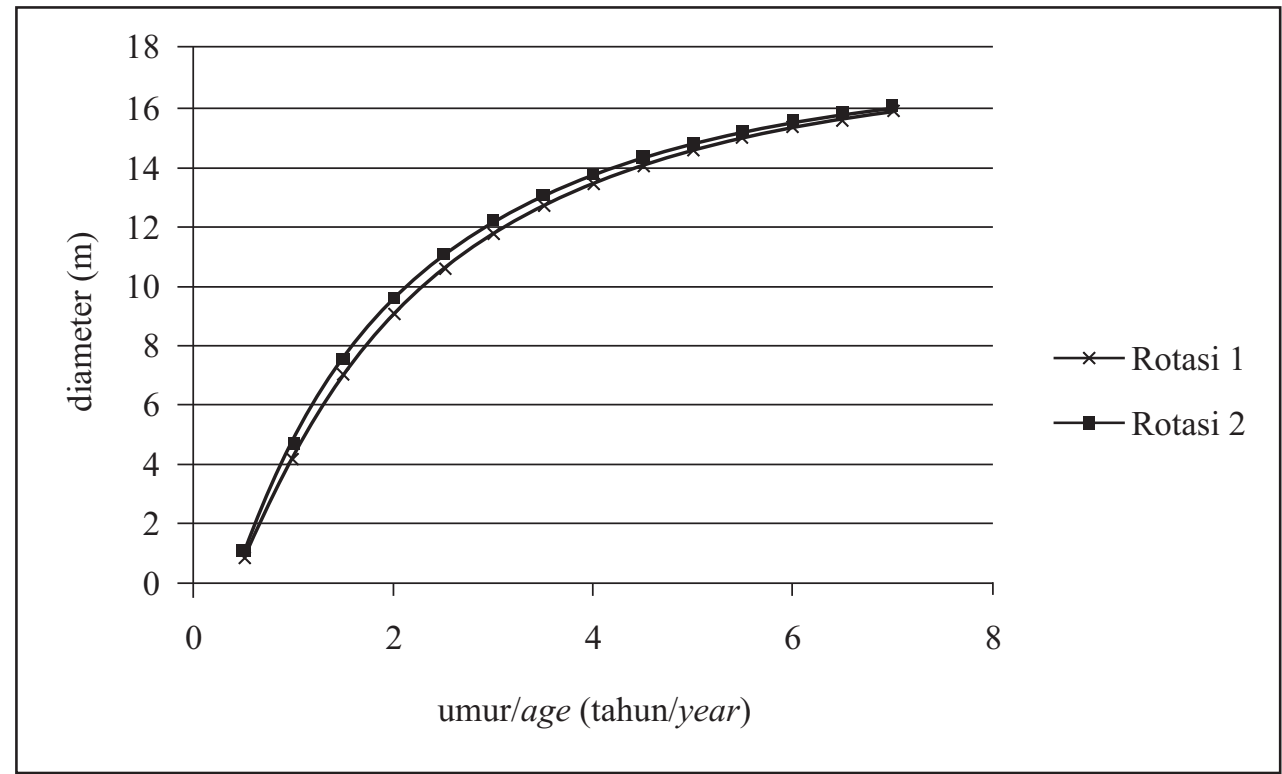

Gambar(Figure) 3. Kurva hubungan antara diameter dan umur tegakan E. urograndis (Curve of the correlation between diameter and ages of E. urograndis) 


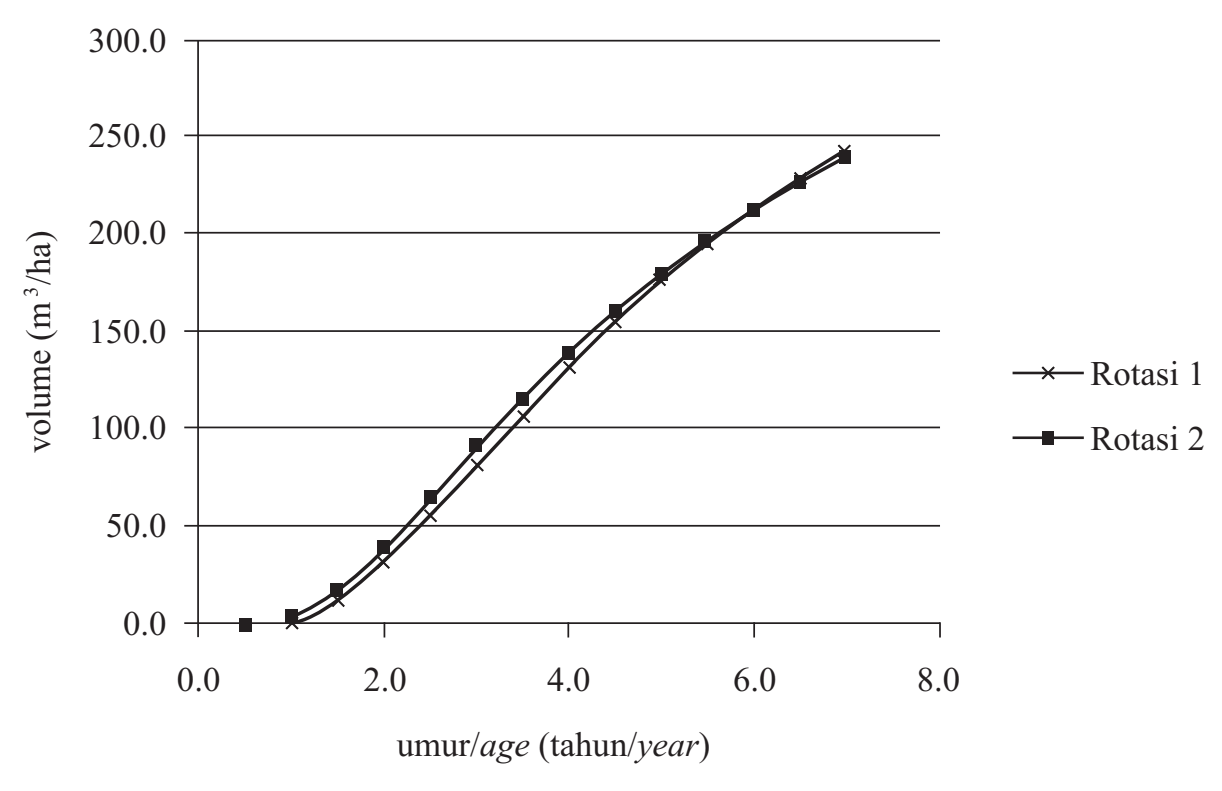

Gambar(Figure) 4. Kurva hubungan antara volume dan umur tegakan E. urograndis (Curve of the correlation between volume and ages of E. urograndis)

Tabel(Table) 1. Model pertumbuhan tinggi (H), diameter (D) dan volume (V) jenis E. urograndis (Growth model of tree height, diameter and volume total for E. urograndis)

\begin{tabular}{|c|c|c|}
\hline $\begin{array}{c}\text { Rotasi } \\
\text { (Rotation) }\end{array}$ & \multicolumn{1}{|c|}{$\begin{array}{c}\text { Persamaan } \\
\text { (Equation) }\end{array}$} & $\begin{array}{c}\mathrm{R}^{2} \\
\text { (Coef. determination) }\end{array}$ \\
\hline \multirow{2}{*}{1} & $\ln \mathrm{H}=3,404349-1,73745(1 /$ umur) & 0,796 \\
& $\ln \mathrm{D}=2,99598-1,56925(1 /$ umur) & 0,891 \\
& $\ln \mathrm{V}=6,300505-5,06804(1 /$ umur) & 0,858 \\
\hline \multirow{2}{*}{2} & $\ln \mathrm{H}=3,342944-1,5336(1 /$ umur) & 0,894 \\
& $\ln \mathrm{D}=2,987992-1,44311(1 /$ umur) & 0,910 \\
& $\ln \mathrm{V}=6,205122-5,06804(1 /$ umur) & 0,888 \\
\hline
\end{tabular}

Pada Tabel 1 dapat dilihat bahwa semua persamaan model pertumbuhan diameter yang dihasilkan mempunyai nilai koefisien determinasi $\left(\mathrm{R}^{2}\right)$ yang baik yaitu nilai $\mathrm{R}^{2}$ lebih dari $75 \%$ untuk rotasi 1 dan lebih dari $85 \%$ untuk rotasi 2. Dengan demikian dapat dikatakan bahwa persamaan-persamaan model pertumbuhan diameter, tinggi dan volume untuk jenis $E$. urograndis pada rotasi 1 dan 2 mempunyai kriteria sebagai model yang baik. Model yang baik pada dasarnya adalah model yang cukup sederhana, mudah untuk dianalisa dan mudah dalam penerapannya, selain itu juga mempunyai ketepatan pendugaan yang cukup tinggi (Latifah, 2000). Beberapa hasil penelitian terdahulu tentang model pertumbuhan jenis Eucalyptus dapat dilihat pada Tabel 2. 
Tabel (Table) 2. Model pertumbuhan tinggi (H), diameter (D) dan volume (V) jenis Eucalyptus (Growth model of height, diameter and volume of Eucalyptus species)

\begin{tabular}{|c|c|c|c|}
\hline $\begin{array}{c}\text { Jenis } \\
\text { (Species) }\end{array}$ & $\begin{array}{l}\text { Persamaan } \\
\text { (Equation) }\end{array}$ & $\begin{array}{c}\text { Lokasi } \\
\text { (Location) }\end{array}$ & $\begin{array}{c}\text { Pustaka } \\
\text { (References) }\end{array}$ \\
\hline E. deglupta & $\begin{array}{l}\text { Ln D }=5,9794-6,2469(1 / A)^{0,2536} \\
\text { Ln } H=4,7984-4,9699(1 / A)^{0,3210}\end{array}$ & Benakat, Sumsel & Harbagung, 1996 \\
\hline E. deglupta & $\begin{array}{l}\text { Ln D }=5,9794-4,8226(1 / A)^{0,2536} \\
\operatorname{Ln} H=4,7984-3,6166(1 / A)^{0,3210}\end{array}$ & $\begin{array}{l}\text { Kenangan, } \\
\text { Kaltim }\end{array}$ & Harbagung, 1996 \\
\hline E. deglupta & $\begin{array}{l}\mathrm{D}=2,64095+3,33076(\operatorname{Ln} \mathrm{A})^{1,81541} \\
\mathrm{H}=2,36047+4,22143(\operatorname{Ln} A)^{1,61350}\end{array}$ & Borisalo, Sulsel & Harbagung, 1991 \\
\hline E. urophylla & $\begin{array}{l}\text { Ln D }=4,0002-4,60841(1 / A)^{0,84327} \\
\text { Ln } H=3,46726-6,83380(1 / A)^{1,38713}\end{array}$ & Pujon, Jatim & Harbagung, 1991 \\
\hline E. urophylla & $\begin{array}{l}\mathrm{D}=\mathrm{e}^{2,64756} \cdot \mathrm{e}^{-1,91553 / \mathrm{A}} \\
\mathrm{H}=\mathrm{e}^{2,759869} \cdot \mathrm{e}^{-1,32222 / \mathrm{A}} \\
\mathrm{V}=\mathrm{e}^{5,706568} \cdot \mathrm{e}^{-4,14016 / \mathrm{A}}\end{array}$ & $\begin{array}{l}\text { Simalungun, Aek } \\
\text { Nauli, Medan }\end{array}$ & Darwo, 1999 \\
\hline E. urograndis & $\begin{array}{l}\text { Rotasi } 1: \\
\ln \mathrm{H}=3,404349-1,73745(1 / \mathrm{A}) \\
\ln \mathrm{D}=2,99598-1,56925(1 / \mathrm{A}) \\
\ln \mathrm{V}=6,300505-5,63547(1 / \mathrm{A}) \\
\text { Rotasi } 2: \\
\ln \mathrm{H}=3,342944-1,5336(1 / \mathrm{A}) \\
\ln \mathrm{D}=2,987992-1,44311(1 / \mathrm{A}) \\
\ln \mathrm{V}=6,205122-5,06804(1 / \mathrm{A})\end{array}$ & $\begin{array}{l}\text { Simalungun, Aek } \\
\text { Nauli, Medan }\end{array}$ & Hasil penelitian ini \\
\hline E. nitens & $\mathrm{V}=0,0049 \mathrm{H}-0,0197$ & Tasmania & Battaglia et al., 1999 \\
\hline E. globulus & $\mathrm{V}=0,0046 \mathrm{H}-0,0196$ & Tasmania & Battaglia et al., 1999 \\
\hline E. globulus & $\begin{array}{l}\mathrm{V}=0,7723 \mathrm{~B}+0,3334 \mathrm{BH}- \\
0,0004361 \mathrm{HN}\end{array}$ & Galicia, Spanyol & Garcia dan Ruiz,2003 \\
\hline
\end{tabular}

Keterangan (Notes) : $\mathrm{A}=$ umur tegakan/age (tahun/year); $\mathrm{B}=$ basal area; $\mathrm{N}=$ jumlah pohon/number of trees

Menurut Chapman dan Meyer (1949); Spurr (1952); dan Alder (1980), pada umumnya model pertumbuhan dengan data pengamatan pertumbuhan dimana pengamatan pada suatu umur terpisah dengan umur lainnya, maka akan diperoleh grafik pertumbuhan yang lebih tegak dibandingkan trend pertumbuhan sebenarnya, sedangkan pada kejadian yang sebaliknya akan diperoleh grafik yang lebih datar.

Hasil uji kesahihan model berdasarkan pada besarnya koefisien determinasi terkoreksi $\left(\mathrm{R}^{2}\right.$ adj), khi-kuadrat dan efisiensi model terenduksi (MEF adj) dapat dilihat pada Tabel 3.

Tabel(Table) 3. Uji kesahihan model pertumbuhan E. urograndis rotasi 1 dan 2 (Validity test of $\mathrm{E}$. urograndis growth model in rotation 1 and 2)

\begin{tabular}{|l|c|c|c|c|c|c|c|c|}
\hline \multirow{2}{*}{$\begin{array}{l}\text { Persamaan } \\
(\text { Equation })\end{array}$} & \multicolumn{4}{|c|}{ Rotasi (Rotation) 1} & \multicolumn{4}{c|}{ Rotasi (Rotation) 2} \\
\cline { 2 - 10 } & $\mathrm{R} 2$ adj & $\chi^{2}$ & $\chi^{2}$ tab & MEF adj & $\mathrm{R}^{2}$ adj & $\chi^{2}$ & $\chi^{2}$ tab & MEF adj \\
\hline Tinggi & 0,789 & 0,15 & 6,57 & 0,932 & 0,893 & 0,03 & 0,71 & 0,941 \\
\hline Diameter & 0,888 & 0,12 & 6,57 & 0,939 & 0,909 & 0,04 & 0,71 & 0,959 \\
\hline Volume & 0,853 & 1,28 & 6,57 & 0,927 & 0,887 & 0,09 & 0,71 & 0,981 \\
\hline
\end{tabular}

Dari Tabel 3 tersebut terlihat bahwa persamaan model pertumbuhan tinggi, diameter dan volume jenis $E$. urograndis selaras atau sama dengan kecenderungan bentuk pertumbuhan sebenarnya baik untuk rotasi 1 maupun rotasi 2 di lokasi sektor Aek Nauli. Hal tersebut dilihat dari nilai determinasi terkoreksi sebesar $>78 \%$ untuk rotasi 1 dan $>88 \%$ untuk rotasi 2 ; nilai khi- 
kuadrat $X^{2}<X^{2}$ tabel (tidak berbeda nyata) dan nilai efisiensi model tereduksi (MEF adj) sekitar $92 \%$ - 93\% untuk rotasi 1 dan $94 \%$ - 98\% untuk rotasi 2. Nilai-nilai tersebut memberikan arti bahwa model persamaan yang dihasilkan di atas sahih dan dapat digunakan untuk menggambarkan perkembangan tinggi, diameter dan volume tegakan hutan tanaman $E$. urograndis di daerah Aek Nauli atau minimal di daerah lain yang kondisi lingkungannya sama dengan lokasi penelitian.

\section{B. Pendugaan Volume Tegakan}

Berdasarkan model pertumbuhan di atas, maka perhitungan pendugaan volume tegakan berdasarkan umur untuk jenis E. urograndis di sektor Aek Nauli, PT Toba Pulp Lestari, Simalungun Sumatera Utara dapat dilihat pada Tabel 4.

Tabel (Table) 4. Volume dugaan $\left(\mathrm{m}^{3} / \mathrm{ha}\right)$ jenis E. urograndis rotasi 1 dan 2 (Prediction of volume $\left(\mathrm{m}^{3} / \mathrm{ha}\right)$ of E. urograndis rotation 1 and 2)

\begin{tabular}{|c|c|c|c|c|c|c|}
\hline \multirow{2}{*}{$\begin{array}{c}\text { Umur/Age } \\
(\text { tahun/year })\end{array}$} & \multicolumn{3}{|c|}{ Rotasi (Rotation) 1} & \multicolumn{3}{c|}{ Rotasi (Rotation) 2} \\
\cline { 2 - 7 } & $\begin{array}{c}\text { Volume } \\
\left(\mathrm{m}^{3} / \mathrm{ha}\right)\end{array}$ & $\begin{array}{c}\text { MAI } \\
\left(\mathrm{m}^{3} / \mathrm{ha}\right)\end{array}$ & $\begin{array}{c}\text { CAI } \\
\left(\mathrm{m}^{3} / \mathrm{ha}\right)\end{array}$ & $\begin{array}{c}\text { Volume } \\
\left(\mathrm{m}^{3} / \mathrm{ha}\right)\end{array}$ & $\begin{array}{c}\text { MAI } \\
\left(\mathrm{m}^{3} / \mathrm{ha}\right)\end{array}$ & $\begin{array}{c}\text { CAI } \\
\left(\mathrm{m}^{3} / \mathrm{ha}\right)\end{array}$ \\
\hline 0 & 0 & - & - & 0 & - & - \\
0,5 & 0,0 & 0,01 & 0,01 & 0,0 & 0,04 & 0,04 \\
1,0 & 1,9 & 1,94 & 3,88 & 3,1 & 3,12 & 6,20 \\
1,5 & 12,7 & 8,48 & 21,56 & 16,9 & 11,26 & 27,53 \\
2,0 & 32,5 & 16,27 & 39,65 & 39,3 & 19,65 & 44,82 \\
2,5 & 57,5 & 22,87 & 49,27 & 65,2 & 26,09 & 51,87 \\
3,0 & 83,3 & 27,75 & 52,15 & 91,4 & 30,48 & 52,44 \\
3,5 & 108,9 & 31,11 & 51,26 & 116,4 & 33,26 & 49,92 \\
4,0 & 133,2 & 33,29 & 48,56 & 139,5 & 34,88 & 46,20 \\
4,5 & 155,7 & 34,61 & 45,13 & 160,6 & 35,69 & 42,18 \\
5,0 & 176,5 & 35,30 & 41,55 & 179,7 & 35,95 & 38,29 \\
5,5 & 195,6 & 35,56 & 38,09 & 197,1 & 35,83 & 34,70 \\
6,0 & 213,0 & 35,50 & 34,86 & 212,8 & 35,47 & 31,46 \\
6,5 & 229,0 & 35,22 & 31,92 & 227,1 & 34,94 & 28,57 \\
7,0 & 243,6 & 34,80 & 29,25 & 240,1 & 34,30 & 26,01 \\
\hline
\end{tabular}

Hasil di atas belum maksimal jika dibandingkan dengan jenis yang sama yang dikembangkan di Brazil. Di Sumatera jenis ini (Tabel 4) pada umur 7 tahun dapat menghasilkan volume dugaan sekitar $240 \quad 245 \mathrm{~m}^{3} / \mathrm{ha}$, sedangkan di Brazil dengan daur 7 tahun dapat menghasilkan kayu bahan pulp dan kertas sebanyak $650 \mathrm{~m}^{3} /$ ha dalam skala penelitian dan $500 \mathrm{~m}^{3} /$ ha dalam skala operasional. Menurut Gonçalves et al. (1997) pertumbuhan E. urograndis di Brazil pada tanah ultisol sangat beragam dengan kisaran riap rata-rata tahunan (MAI) pada umur 5 tahun sebesar $1248 \mathrm{~m}^{3} /$ ha/tahun. Sedangkan di Congo produktivitas hibrid E. urograndis sangat tinggi dan memiliki riap tahunan rata-rata sebesar $70 \mathrm{~m}^{3} /$ ha/tahun (Campinhos, 1993). Pendugaan biomassa hibrid E. grandis (E. urograndis) pada umur 6 tahun dapat mencapai $95 \mathrm{~m}^{3} / \mathrm{ha} /$ tahun jika jenis ini ditanam pada lahan yang cukup air (Almeida $e t$ al., 2007).

Apabila kita bandingkan hasil pertumbuhan volume dugaan $E$. urograndis dalam penelitian ini dengan hasil penelitian jenis $E$. urophylla yang merupakan tanaman tetuanya dari lokasi yang sama (Darwo, 1999), maka volume dugaan untuk jenis $E$. urograndis lebih tinggi (Tabel 2) dan akan lebih tinggi lagi jika volume dugaan didasari pada volume seluruhnya, bukan dengan volume yang termanfaatkan saja. Hasil penelitian terhadap jenis E. urophylla menunjukkan bahwa riap potensi tegakan optimal terjadi pada umur 5 tahun dengan $M A I$ sebesar $26,29 \mathrm{~m}^{3} /$ ha/tahun, $C A I 24,58 \mathrm{~m}^{3} / \mathrm{ha} /$ tahun dan potensi tegakan sebesar $131,44 \mathrm{~m}^{3} / \mathrm{ha}$. Perbedaan ini jelas diakibatkan perbedaan kualitas bibit secara genetik karena bibit $E$. urophylla yang digunakan berasal dari biji, sedangkan jenis tegakan E. urograndis berasal berasal dari bibit secara vegetatif dari klon yang 
telah teruji dan merupakan hasil persilangan antara E. urophylla dengan E. grandis.

\section{Penentuan Daur Optimal}

Penentuan daur optimal dilakukan berdasarkan laju pertumbuhan tegakan per satuan waktu yang disebut riap tegakan. Daur optimal tegakan dilihat dari riap pertumbuhan maksimal yang ditentukan berdasarkan telah adanya titik potong antara kurva riap tahunan berjalan $(C A I)$ dengan riap rata-rata tegakan (MAI). Titik perpotongan yang terjadi merupakan daur dimana riap volume maksimal dapat dicapai dan pada umumnya perusahaan menggunakan waktu terjadinya titik potong ini sebagai waktu panen karena memberikan hasil yang maksimal. Kurva CAI dan MAI tegakan E. urograndis di PT Toba Pulp Lestari pada rotasi 1 dapat dilihat pada Gambar 5 dan rotasi 2 pada Gambar 6.

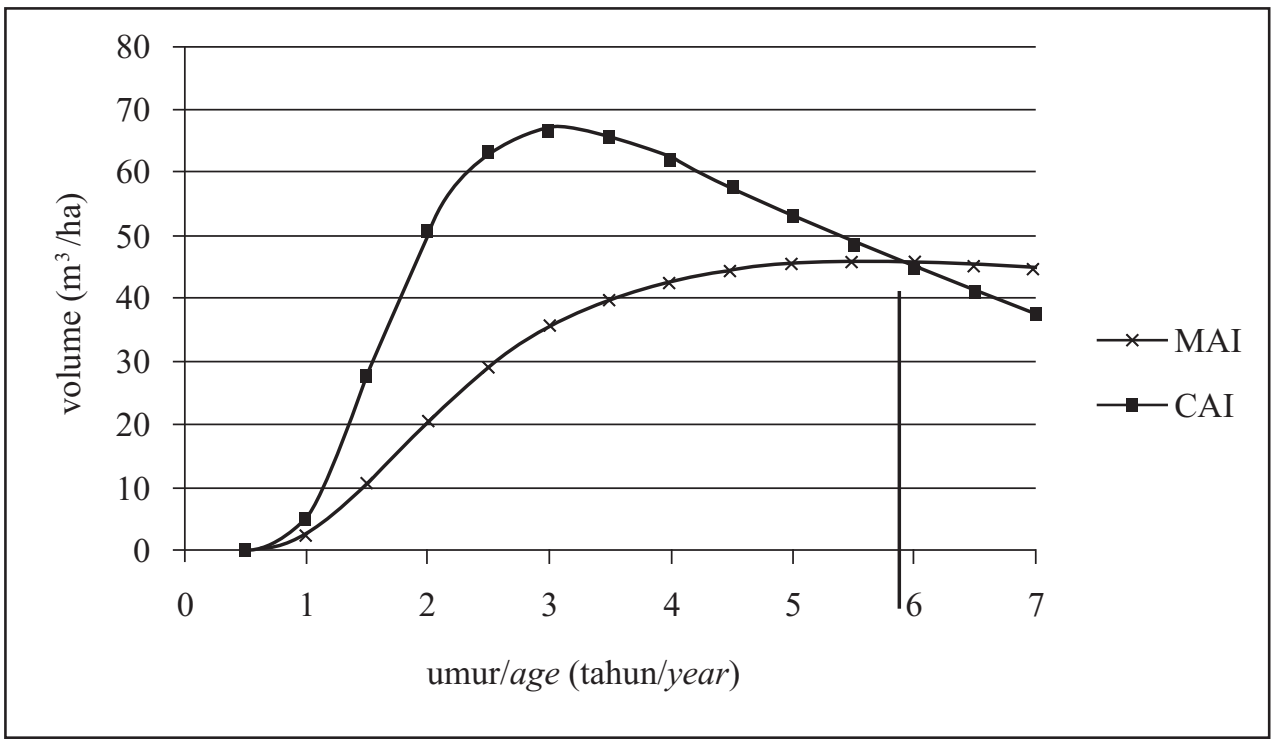

Gambar(Figure) 5. Daur volume optimal rotasi 1 jenis E. urograndis (Optimal volume cycle of E. urograndis rotation 1 and 2)

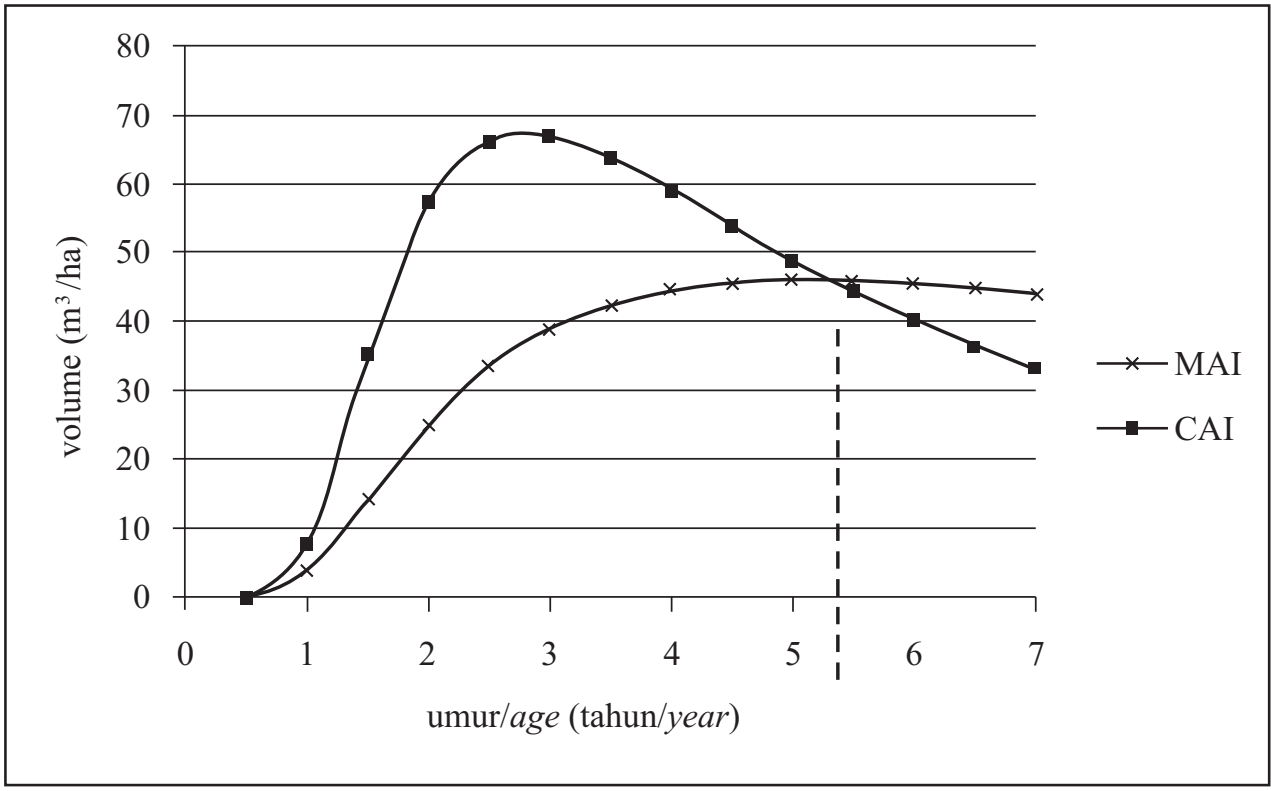

Gambar(Figure)6. Daur volume optimal rotasi 2 jenis E. urograndis (Optimal volume cycle of E. urograndis rotation 1 and 2 ) 
Dari data dimensi tegakan hasil pengukuran PSP pada daur pertama yang dituangkan dalam sebuah model pertumbuhan, diketahui bahwa pertumbuhan riap volume optimal tegakan E. urograndis terjadi pada umur antara 5,5-6,0 tahun. Hal ini terlihat pada Gambar 5, dimana pada kisaran umur tersebut terjadi perpotongan antara grafik MAI dan CAI. Oleh karena itu pada rotasi pertama tegakan sebaiknya dipanen pada umur 5,5 tahun agar tegakan menghasilkan kayu dengan riap tertinggi sekitar $35,56 \mathrm{~m}^{3} / \mathrm{ha}$. Sedangkan untuk rotasi kedua perpotongan grafik MAI dengan CAI terjadi pada umur antara 5 tahun $-5,5$ tahun. Hal ini menunjukkan bahwa tegakan $E$. urograndis rotasi kedua paling optimal riapnya terjadi pada umur sekitar 5 tahun dengan riap volume sekitar $35,95 \mathrm{~m}^{3} / \mathrm{ha}$, sehingga disarankan dilakukan pemanenan pada umur 5 tahun.

\section{KESIMPULAN DAN SARAN}

\section{A. Kesimpulan}

1. Gambaran perkembangan tinggi, diameter dan volume tegakan hutan tanaman jenis Eucalyptus urograndis dapat didekati dengan persamaan :

$\ln \mathrm{H}=3,404349$ - 1,73745 (1/umur)

$\ln \mathrm{D}=2,99598 \quad-1,56925$ (1/umur)

$\ln \mathrm{V}=6,300505$ - 5,63547 (1/umur) untuk rotasi 1 , sedangkan untuk rotasi 2 bentuk persamaannya adalah :

$\ln \mathrm{H}=3,342944$ 1,5336 (1/umur)

$\ln \mathrm{D}=2,987992-1,44311$ (1/umur)

$\ln \mathrm{V}=6,2051225,06804$ (1/umur).

2. Volume dugaan tegakan E. urograndis baik pada rotasi 1 maupun rotasi 2 menunjukan hasil yang cukup tinggi dimana pada umur tebang $5-5,5$ tahun volume yang dihasil-kan dapat mencapai sekitar $176-197 \mathrm{~m}^{3} / \mathrm{ha}$.

3. Daur optimal pada rotasi 1 terjadi pada umur 5,5 tahun dengan riap volume maksimal tegakan E. urograndis (MAI) sekitar 35,45 $\mathrm{m}^{3} /$ ha/tahun dan pada rotasi 2 terjadi pada umur 5 tahun dengan riap volume maksimal sebesar $35,95 \mathrm{~m}^{3} / \mathrm{ha} /$ tahun.

\section{B. Saran}

1. Penelitian perlu dilanjutkan dengan pengukuran dimensi tegakan sepanjang daur secara periodik pada petak ukur permanen agar model pertumbuhan lebih mendekati keadaan pertumbuhan sebenarnya.

2. Perlu dilanjutkan penelitian ini dengan melihat hubungan antara pertumbuhan dengan sifat-sifat lingkungan yang mempengaruhinya (tanah, iklim, habitat, dll).

\section{UCAPAN TERIMA KASIH}

Terima kasih disampaikan kepada PT Toba Pulp Lestari yang telah mengijinkan penelitian di lokasi tersebut dan memberikan data sekunder berupa data dimensi tegakan pada petak ukur permanen (Permanen Sample Plot) jenis Eucalyptus urograndis.

\section{DAFTAR PUSTAKA}

Alder, D. 1980. Forest Volume Estimation and Yield Prediction. Vol 2- Yield prediction. FAO. Rome.

Almeida, A.C., J.V. Soares; J.J. Landsberg and G.D. Rezende. 2007. Growth and water balance of Eucalyptus grandis hybride plantations in Brazil during a rotation for pulp production. Forest Ecology and Management $251: 10-21$.

Avery, T. E. and H. E. Burkhart. 2002. Forest Measurements. McGraw-Hill. New York.

Battaglia, M., P.J. Sands and S.G. Candy. 1999. Hybrid groth model to predict height and volume growth in young Eucalyptus globulus plantation. Forest Ecology and Management 120: 193-201.

Campinhos, E. N. 1993. A Brazilian example of a large scale forestry plantation in tropical region: Aracruz. In : J. Davinson (ed.). Proc. of the regional symposium on recent advances in mass clonal multiplication of forest trees for plantation programmes . FAO. Los Banos. Philipines.pp.46-59.

Chapman, H. H. and W.H. Meyer. 1949. Forest Mensuration. McGraw-Hill Book Company. Inc. New York-Toronto-London.

Darwo 1999. Kajian riap dan pertumbuhan tiga jenis tanaman HTI. Prosiding ekspose hasil penelitian Balai Penelitian Kehutanan Pematang Siantar, Medan, 30 Maret 1999. Balai Penelitian Kehutana Pematang Siantar, Badan Litbang Kehutanan 
dan Perkebunan. Departemen Kehutanan dan Perkebunan. Jakarta.

Garcia, O. and F. Ruiz. 2003. A growth model for eucalypt in Galicia, Spain. Forest Ecology and Management $173: 49-62$.

Gonçalves, J. L. M. N. F. Barros, E.K.S Nambiar and R. F. Novais. 1997. Soil and stand management for short rotation plantations. In Nambiar, E K S and A G Brown (eds); Management of Soil Nutrient and Water in Tropical Plantation Forest. ACIAR. Australia.

Harbagung. 1991. Model pertumbuhan diameter dan tinggi tegakan hutan tanaman Eucalyptus urophylla S.T.Blake di daerah Pujon, Jawa Timur. Bulletin Penelitian Hutan. No. 545:11-27.

Harbagung. 1991. Model pertumbuhan diameter dan tinggi tegakan hutan tanaman Eucalyptus deglupta BL. di Borisalo, Sulawesi Selatan. Bulletin Penelitian Hutan. No. 536:1-16.

Harbagung. 1996. Model pertumbuhan diameter dan tinggi tegakan hutan tanaman Eucalyptus deglupta BL. di Benakat, Sumatera Selatan dan Kenangan, Kalimantan Timur. Bulletin Penelitian Hutan. No. 599:15-31.

Huang, S. Y. Yang. and Y. Wang. 2003. A critical look at procedures for validating growth and yield models. In: Amaro. A. D. Reed. and P. Soares. (eds.). Modelling Forest Systems. CAB International. Wallingford. pp. 271-293.

Husch, B. 1963. Forest Mensuration and Statistics. The Ronald Press Company. New York.

Husch, B. T. W. Beers and J. A. Kershaw. 2003. Forest Mensuration. Fourth Edition. John Wiley and Sons. Inc. New York.

Kutner. M. H., C. J. Nachtsheim. J. Neter and W. Li. 2005. Applied Linear Statistical Models. McGraw-Hill Irwin. Boston.
Latifah. S. 2000. Keragaan pertumbuhan Acacia mangium Willd. pada lahan bekas tambang timah (Studi kasus di areal kerja PT. Timah TBK). Sekolah Pascasarjana. Institut Pertanian Bogor.

Nikles, D. G. 1996. The first 50 year of the evolution of forest tree improvement in Queensland. In Dieters. M.J. Matheson. A.C., Nikles.D.G.. Harwood. C.E. and Walker. S.M. (eds). Tree Improvement for Sustainable Tropical Forestry. Proc. QFRI-IUFRO Conf. Caloundra. Queensland. Australia. 27-October-1 November 1996.pp51-64.

Pasaribu, A. R. dan A. Tampubolon. 2007. Status teknologi pemanfaatan serat kayu untuk bahan baku pulp. Makalah pada sosialisasi program dan kegiatan BPHPS. Balai Penelitian Hutan Penghasil Serat. Kuok.Pekanbaru.

Soares, P. M. Tome. J. P. Skovsgaard. and J. K. Vanclay. 1995. Evaluating a growth model for forest management using continous forest inventory data. For. Ecol. Manage. 71:251-265.

Sokal, R. R. and F. J. Rohlf. 1995. Biometry the Principles and Practice of Statistics in Biological Research. W.H. Freeman. New York.

Spurr, S. H. 1952. Forest Inventory. The Ronald Press Co. New York.

Steel, R. G. D. and J. H. Torrie. 1980. Principles and Procedures of Statistics. Second Edition. McGraw-Hill Book Company. Inc. New York.

Toba Pulp Lestari. 2009. Data Dasar Keadaan Umum PT Toba Pulp Lestari. Porsea.

Vanclay, J. K. 1994. Modelling Forest Growth and Yield. Application to mixed tropical forest. CAB International. Guildford.

Vanclay, J. K. and J. P. Skovsgaard. 1997. Evaluating forest growth models. Ecol. Model. 98: 7-42. 